\title{
Analysis of the Influence of Authentic English Videos on Technical Students' Memorization and Subsequent Recall of the English Lexis
}

\author{
M. Shevchenko
}

National Technical University of Ukraine "Igor Sikorsky Kyiv Polytechnic Institute"
Corresponding author. E-mail: marianashevchenko@ ukr.net

Paper received 05.02.18; Revised 08.02.18; Accepted for publication 09.02.18.

https://doi.org/10.31174/SEND-PP2018-155VI65-11

Abstract. The article deals with the influence of authentic English videos on technical students' memorization and subsequent recall of the English lexis. The process of the brain and memory work when students are exposed to videos in class is clarified. According to the data analysed, clips from English movies and programmes are valuable educational aids in teaching English as a foreign language. This has been verified experimentally. The results of authentic videos' influence on the students' memorization and recall of the English lexis, as well as motivation to continue studying English are provided.

Keywords: videos, English, vocabulary, recall, technical students.

Introduction. One of the main, if not the main, tasks of the educators that teach English as a foreign language is the organization of study in such a way that students are constantly interested and motivated to continue improvement of their foreign language proficiency level. Authentic English materials have no competitors in this matter. Among the aforementioned aids, the most beneficial in the English class are videos (clips) from feature films and TV programmes. They have the influence on students' attention to educational data, memory, and studied vocabulary and grammar recall.

A brief review of publications on the subject. The importance of videos and different types of multimedia aids has been mentioned by numerous researchers. Aloraini (2012) [2] explores the influence of multimedia use on students' academic achievement, new educational materials understanding, and their further application. Yamauchi's (2008) [12] study results showed that students' learning and perception were significantly advanced after viewing the instructional DVD, which provided factual data and strengthened instructional material. Mayer (2001) [6] studies the benefits of multimedia learning, making use of multimedia presentations in which students learn from both words and images, not just texts. The cognitive theory, which bases on the dual-channel perception of information, is one of the key focuses of the researcher's work. Oxford and Scarcella (1994) [9] point out the importance of context for the adults' second language vocabulary studying.

However, the influence of authentic English videos, including clips from films and programmes, on memorization and subsequent recall of the English lexis by students of technical specialties is still not fully examined, and a more in-depth analysis is needed.

The goal of the research is the comprehensive examination of the influence of authentic English videos on technical students' memorization and subsequent recall of the English lexis.

Materials and methods. In the course of study the article's subject matter, various types of literature were analysed, including pedagogical and psychological. The reason for studying the works belonging to the two mentioned branches of science was their interrelation when it comes to investigation of peculiarities of students' processes of memorization and recall of lexis in the foreign language. The theoretical data collected and presented in the current paper were tested in practice in the form of an experiment. The pre- and post-study results are provided further in the article.

Results and discussion. Little can be expressed if one does not know grammar, but nothing can be expressed if one does not know any lexis. It is impossible to learn any language, especially foreign, without the acquisition of vocabulary. The speaker's thought can be formed and formulated differently with the help of the same linguistic means, i.e. the same lexicon and grammar. To do so, students of technical specialties need to increase their active and passive lexical minima, which include not only the professional terminology but also the commonly used vocabulary. However, the acquisition of a sufficient number of words is challenging: the fundamental number of foreign language words is 2000 word families, and if the learner wishes to read newspapers or books, they must know approximately 8000 to 9000 word families [8, p. 59-60]. To say that a student has vocabulary knowledge, they should possess the item and system features of vocabulary (have the item and system knowledge). The former means being able to recognize word items (a word or its forms), and the latter - being able to understand different features of word items (phonological, orthographic, and semantic), including a word's relationship with other words in an individual's mental vocabulary, association [7, p. 23]. At present, the foreign language vocabulary learning is mostly done via demonstrating words in a certain context, and the out-of-the-context approach (memorization of a list of non-interconnected words) is considered obsolete and ineffective [4].

It is a common belief that students should be invigorated to seek opportunities to use the studied foreign language outside the class. Extensive self-initiated listening, reading, and use of the English language in informal ambience boost knowledge of a wide range of frequently used words [13, p. 64]. As confirmed by the results of the experiment, provided further in the article, videos, namely, clips from movies and TV programmes are useful educational aids in teaching students of technical specialties the English language as a foreign one. This is due to the fact that they present the studied vocabulary in context and, in addition to that, can be easily used by the students outside the classroom environment - at home or even café, where the Internet is available to watch online or download videos in English (with or without subtitles in the same language). It is helpful as long as linguists have noticed that the more people watch and listen, or 
read in a foreign language, the more opportunities they have to encounter new words in context. Regular practice enables people not only to acquire new vocabulary but also to consolidate their knowledge of lexis.

Moreover, the use of videos adds visual memory to perceptively mnemonic activity. According to data from numerous experiments, the number of people having a visual memory type exceeds the number of people with other types of memory. The visual memory has such significant advantages as power and correctness of memorization in comparison with the verbal-auditory one [16, p. 27-28].

Any lexis recall starts with its preceding retention. Since the issue analysed is closely related to psychology, namely, the psychological peculiarities of the memory work, it is worth noting the process of the brain- and memory work during the study of the English vocabulary with videos by students of technical specialties.

When the information is heard and/or seen, it gets into the cognitive system in the brain via acoustic or visual channels and is held in a short-term storage to achieve some mental activity (language development and comprehension, problem-solving, etc.). It is known as the working memory. If these data are held there long enough and have not been forgotten, they are transferred to the longterm memory [3].

The process of learning a new word involves establishing both a phonological and semantic representation of the word and forming a link between the two [5]. When students are exposed to authentic English videos while studying EFL (English as a foreign language), just such a process occurs: students hear a word or a wordcombination and (try to) infer the meaning of the newly encountered vocabulary items, i.e. their semantics, from the context using the visual representation of the situation the word(s) appears in. An additional proven benefit of using videos in teaching students EFL is that subsequent recall is superior for words presented via the auditory modality over the visual modality (for instance, in the form of a printed word-list) [11].

Often students say that they have problems with the English lexis memorization, especially technical one, mainly because they have a bad memory. In fact, the reason for their bad vocabulary recall can be poorly developed memory habits, from recognition memory perspective. Among such memory habits, or strategies, are laying things out in order, making the association, and reviewing. These principles are employed when a student faces the challenge of lexis learning. Words, wordcombinations, and phrases can be associated with visual images-in our case, from movies and programmes-that can be stored and ulteriorly retrieved for communication. Many students make use of visual images, but some find it easy to link words, their combinations, and phrases with sound [10 as cited in 1, p. 84]. Thus, university English educators should carefully consider what aids to use in class in order to launch their students' ability to qualitatively acquire, memorize, and recall new educational information related to their specialty and presented in English as a foreign language, using association when needed. Particular attention should be paid to the technique of memorizing foreign words, since a large number of new terms are a serious obstacle to studying a foreign language, in particular, English.

Authentic English videos help not only present the learned information or a subject matter in class but they also create the associative link between the heard words or phrases, their semantics (meaning) in the context shown on the video, and the students' general and/or specialty background knowledge. Thus, programmes or film extracts influence students' memorization by grasping their attention and embolden them to watch, listen, and try to comprehend all the details. Afterwards, during the post-watching classwork, the new words will be stored in the working (short-term) memory, applied practically, associatively connected with the students' previous knowledge, and subsequently transferred to the longterm memory in the form of interrelated visual and sound representation of the studied information. Concepts and their visual images will be saved in the memory together. The concepts on which meaning is based are represented in memory as nodes that are associated with other nodes through connecting associations or links. The power of association in the link between nodes is largely due to students' prior learning experience [1, p. 85]. Words in the foreign language, especially technical terminology, need to be memorized so that in the future they could cause the corresponding visual images in the brain during the perception. In this case, the retrieval of a word's translation in the native language will not be needed every time: the word will simply be understood without any translation process, as it happens when one comes across a word or a phrase in their native language.

The general provisions of the associative psychology, which are applicable when authentic video records are used in the EFL class, can be formulated as follows: a certain image is perceived, it corresponds to a word. This word is present in the language native to a person and has a corresponding word which denotes the same image or concept in the foreign language. Thus, a chain is created: the object/concept - its image (representation) - the image of the word of the native language - the image of the word of the foreign language [15].

With English videos in the EFL class, the memorization of foreign words is carried out in stages: 1) studied vocabulary is presented as visual images, e.g. demonstration of events in a movie clip or the principles of a device work on a video - TV programme; 2) visual images of several words are remembered in the appropriate sequence (it is necessary for correct word order in wordcombinations during the further recall); 3) when a direct connection between the word and the image is made, associations are added to memorize them better and connect with the prior knowledge; 4) the pronunciation (sounding) of a word(s) in the foreign language is remembered; 5) in order to save the new lexis in the longterm memory, it is repeated multiple times, e.g. while doing post-listening exercises; 6) the concept, its image, and the sounding in English join firmly in the memory.

The memorization of the pronunciation of any word in the foreign language heard on the video may be done with the help of [14]:

1) the method of leading associations (encoding according to a similar sound; attachment to well-known information); 
2) phonetic codes (when there are no similarities in words' sounding in the foreign and native languages);

3) the method of an associative link creation (with the allocation of the basis of the association).

Watching authentic English videos in the English language class at the university, students' visual images created in the coding process can easily be memorized sequentially, and during the recall, they will prompt (point out) the word or technical term they need to communicate in English. As a result of repetitions in the imagination, words that are remembered in the form of images are fixed in memory and then reproduced directly (immediately as an audio message) in the target language. Thus, students of technical specialties master new lexis better with the help of the system of associations. They are used as memory keys at the first stage of new vocabulary studying, are easily captured in memory, and allow enriching students' vocabulary for an exceptionally short term.

After the automatization of a word recall in English is reached, students of technical specialties will no longer need to think of artificial associations and word coding in their native language to remember the English word's meaning, instead they will automatically recollect its visual image when they hear it in the foreign language, and vice versa. This connection forms rapidly. It can be felt by the appearance of the immediate recall effect. However, it should be remembered that the mentioned effect appears quickly only if the word practice is done actively and repeatedly at the university and, it is advisable, at home as well.

At the time of post-listening work with new words (practical application), it is recommended to remind students about the prefixing and suffixing of the studied words. This broadens the students' vocabulary greatly, enabling them to put the new terminology in combinations with already known words while changing grammatical constructions.

Experimental verification. In order to check in practice whether authentic English videos actually have apparent influence on technical students' memorization and subsequent recall of the English lexis, an experiment was conducted at the Institute of Energy Saving and Energy Management (IEE) of the National Technical University of Ukraine "Igor Sikorsky Kyiv Polytechnic Institute" in December, 2017. Two groups of the six-year students were selected for a 4-week experiment. The experimental group was studying with the use of authentic videos (clips from Hollywood films) in English, and the control group was using only printed materials (the course book and handouts) during their study. For the accuracy of the experiment, an equal number of students (15) with the approximately equal level of English proficiency were chosen for each group from different departments of the IEE: Department of Power Supply, Department of Electromechanical Equipment for Energy-Consumption Industries, Department of Electric-Complexes Control Automation, and Department of Geoengineering. The selection of students for each group was done with the help of preexperimental testing of the English language knowledge. At that, the main attention was paid to the students' understanding of English lexis and its application - listening and speaking. Students' writing skills were not tested.
The IEE students of the aforementioned departments study engineering, ecology, and energy saving. Their future jobs will comprise elements of these scientific spheres. Thus, the teaching aids of group 1 were presented by numerous fragments (made from licensed DVDs and YouTube videos) of two Hollywood films - 'A Civil Action' (1998) and 'Erin Brockovich' (2000). These movies were intentionally selected since they depict topics that correspond to one of the aspects of the IEE students' specialty - ecological issues and their influence on the environment, with direct reference to engineering. The clips were specially made for an average duration of 5 minutes each. These videos were used throughout the EFL lesson, and all activities were based on them in some way. At first, they played the role of the basis (a topic presentation), and later on - the support (serving as examples during the communicative exercises) and the stimuli (used during the development of students' speaking skills with the help of conditionally communicative and communicative-productive tasks). Various exercises were used to promote the IEE students' topics comprehension, lexis and grammar studying, and communication skills development. The assignments were presented in increasing complexity - from the simplest (with props and handouts) to the most intricate (self-prepared monologues and dialogues on the lesson's subject matter).

Among the main educational tasks of the experimental EFL lessons with authentic English videos was the improvement of technical students' memorization and subsequent recall of the English lexis (general and technical), enhancement of the topics understanding, and students' communication skills. They were tested on the post-study test.

Results of the research. The post-experiment test results have shown that the knowledge of the studied English vocabulary of group 1 (who studied with authentic English videos) had been improved noticeably: the number of people who, evidently, could correctly memorize the terminology and subsequently recall it in the maximum amount on the test after 4 weeks of study was $86.7 \%$ (13 out of 15 students). Compared with the initial results (pre-experimental testing) of the group, which was $53.3 \%$ ( 8 out of 15), the outcome advanced almost twofold. The coefficient of improvement was 1.63. Moreover, students showed the ability to operate various forms of the studied words, using different prefixes and suffixes. They also demonstrated the understanding of the lessons' topics and attentiveness to details. Whereas, the results of group 2 (who used solely printed educational materials) did not show much improvement since the pre-study testing. Only 9 people out of 15 showed visible results of the studied lexis recall, and so its memorization: $60 \%$ of the group. Therefore, the difference ration between the preliminary results, which were 7 out of $15(46.7 \%)$, and the poststudy ones was not sizeable -1.28 .

Comparing the outcome of the experiment (the coefficients of improvement) seen on the post-study testing, group 1 performed 1.3 times better than group 2 in memorizing and recollection of the new English lexis provided in the EFL lessons at the university.

It was possible to advance the group 1 students' knowledge of the English vocabulary due to the improvement of their memorization and recall skills owing 
to the clips from the authentic English resources - Hollywood films. An extra benefit of the used multimedia aids was the increased proactivity of the IEE students of the mentioned group and their interest in the further foreign language studying. $80 \%$ (12 out of 15 ) of the students, who gave answers in the post-study survey, stated that they had watched the full movies in English, fragments of which they had seen in the EFL class. And 93.3\% (14 out of 15) of them said that they would like to have more of such lessons and would continue films viewing at home for independent English practice, including listening skills further development. At the same time, the students of group 2, who studied English using only printed materials, declared that there was no improvement of their interest in and motivation to study English additionally at home - only $33.3 \%$ (5 out of 15) of these students said they would continue study after-hours. Thus, the impetus difference ratio of group 1 and group 2 is 2.8 (93.3\% to $33.3 \%$ ), i.e. almost 3:1.

The total coefficient of improvement, including the English vocabulary memorization and recall, as well as the students' subsequent motivation for further studying English, is as follows: group $1=90 \%$, group $2=46.65 \%$. The difference is 1.9 , meaning that group 1 has twice as good total results than those of group 2 after the conducted study.

The results obtained after the experiment provide an undeniable confirmation of the significant influence of authentic English videos on technical students' memorization and subsequent recall of the English lexis, as well as their importance for the encouragement of students to continue studying English even after-hours.

\section{Conclusions.}

1. Clips from authentic English movies and TV programmes are valuable educational aids in teaching students of technical specialties English as a foreign language because: 1) they present the studied vocabulary in context; 2) they can be easily used outside the classroom environment; 3) they add visual memory to perceptively mnemonic activity; and the visual memory is known as the most prevalent type of memory among people, the benefits of which are correctness of memorization in comparison with the verbal-auditory memory; 4) they create the associative link between the heard words or phrases, their semantics (meaning) in the context shown on the video, and the students' general and/or specialty background knowledge; 5) the subsequent recall is superior for words presented via the auditory modality over the visual modality (for instance, in the form of a printed word-list).

2. During the study of EFL vocabulary with videos, the brain and memory work as follows: when the information is heard and/or seen, it gets into the cognitive system in the brain via acoustic or visual channels and is held in a short-term storage (the working memory) to achieve some mental activity; if these data are held there long enough and have not been forgotten, they are transferred to the long-term memory.

3. When students are exposed to authentic English videos while studying EFL, such a process occurs: students hear a word or a word-combination and (try to) infer the meaning of the newly encountered vocabulary items, i.e. their semantics, from the context using the visual representation of the situation the word(s) appears in; when that is done, concepts and their visual images are saved in the memory together.

4. The reason for students' bad vocabulary recall can be poorly developed memory habits (strategies), from recognition memory perspective, among which are laying things out in order, making the association, and reviewing (these principles are employed when a student faces the challenge of lexis learning).

5. Students of technical specialties master new lexis better with the help of the system of associations. After the automatization of a word recall in English is reached, the students will no longer need to think of artificial associations and word coding in their native language to remember the English word's meaning, instead they will automatically recollect its visual image when they hear it in the foreign language, and vice versa.

6. With English videos in the EFL class, the memorization of foreign words is carried out in stages: 1) the studied vocabulary is presented as visual images, e.g. demonstration of events in a movie clip or the principles of a device work in a TV programme; 2) visual images of several words are remembered in the appropriate sequence (it is necessary for correct word order in wordcombinations during the further recall); 3) when a direct connection between the word and the image is made, associations are added to memorize them better and connect with the prior knowledge; 4) the pronunciation of a word(s) in the foreign language is remembered; 5) in order to save the new lexis in the long-term memory, it is repeated multiple times, e.g. while doing post-listening exercises; 6) the concept, its image, and the sounding in English join firmly in the memory.

7. The memorization of the pronunciation of any word in the foreign language heard on the video may be done with the help of: 1) the method of leading associations (encoding according to a similar sound; attachment to well-known information); 2) phonetic codes (when there are no similarities in words' sounding in the foreign and native languages); 3) the method of an associative link creation (with the allocation of the basis of the association).

8. The explanation of prefixing and suffixing of the studied words is crucial. This broadens the students' vocabulary greatly, enabling them to put the new terminology in combinations with already known words while changing grammatical constructions.

9. The four-week experimental verification of the influence of authentic English videos on technical students' memorization and subsequent recall of the English lexis has shown that the outcome (the coefficient of improvement) of the experimental group (No.1) was 1.3 times better than that of the control group (No.2): $86.7 \%$ (1.63 times better than pre-testing results) and 60\% (1.28 times better) respectively. The total coefficient of improvement (in percentage), including the English vocabulary memorization and recall, as well as the students' subsequent motivation for further studying English, is as follows: group $1=90 \%$, group $2=46.65 \%$. The difference is 1.9 , meaning that group 1 has twice as good total results than those of group 2 after the conducted experiment. 


\title{
REFERENCES
}

1. AL-Hammadi, F. S. (2012). The Role of Recognition Memory in L2 Development. Journal of King Saud University - Languages and Translation. 24, 83-93.

2. Aloraini, S. (2012). The Impact of Using Multimedia on Students' Academic Achievement in the College of Education at King Saud University. Journal of King Saud University Languages and Translation. 24, 75-82.

3. Atkinson, R. C., \& Shiffrin, R. M. (1968). Human Memory: A Proposed System and its Control Processes. In K. W. Spence \& J. T. Spence (Eds.). The Psychology of Learning and Motivation: Advances in Research and Theory (Vol. 2, pp. 89195). New York: Academic Press.

4. Fitzpatrick, T., Al-Qarni, I., \& Meara, P. (2008). Intensive Vocabulary Learning: A Case Study. Language Learning Journal. 36 (2), 239-248.

5. Gupta, P., \& Tisdale, J. (2009). Word Learning, Phonological Short-Term Memory, Phonotactic Probability and Long-Term Memory: Towards an Integrated Framework. Philosophical Transactions of the Royal Society of London. Series B: Biological Sciences. 364, 3755-3771.

6. Mayer, R. E. (2001). Multimedia Learning. New York, NY: Cambridge University Press. 210.

7. Nation, I. S. P. (2001). Learning Vocabulary in Another Language. Cambridge: Cambridge University Press.

8. Nation, I. S. P. (2006). How Large a Vocabulary is Needed for Reading and Listening? The Canadian Modern Language Review. 63 (1), 59-82.
9. Oxford, R. L., \& Scarcella, R. C. (1994). Second Language Vocabulary Learning among Adults: State of the Art in Vocabulary Instruction. System. 22 (2), 231-243.

10. Oxford, R. (2001). Research on Language Learning Strategies: Purpose, Methods, Issues. Presentation, Hokkaido University.

11. Penney, C. G. (1989). Modality Effects and the Structure of Short-Term Verbal Memory. Memory and Cognition. 17 (4), 398-422.

12. Yamauchi, L. G. (2008). Effects of Multimedia Instructional Material on Students' Learning and their Perceptions of the Instruction. Retrospective Theses and Dissertations. Paper 15324. 54.

13. Yang, W., Dai, W. (2011). Rote Memorization of Vocabulary and Vocabulary Development. English Language Teaching. 4 (4), 61-64.

14. Ziganov, M., Kozarienko, V. (2008). Mnemonics. Memorization Based on Visual Thinking. Available: https://www.ereading.club/bookreader.php/131416/Kozarenko,_Ziganov__Mnemotehnika._Zapominanie_na_osnove_vizual'nogo_mys hleniya.html. Last accessed 5th Feb 2018.

15. Zimniaia, I. A. (1985). Psychological Aspects of Learning to Speak in a Foreign Language. 2nd ed. Moscow: Prosveshcheniie. 160.

16. Zinchenko, V. P. (1971). Productive Perception. Psychological Issues. 6, 27-42.

\begin{abstract}
Анализ влияния аутентичных англоязычных видео на запоминание и последующее вспоминание англоязычной лексики студентами технических специальностей

М. В. Шевченко

Аннотация. В статье изучается влияние аутентичных англоязычных видео на запоминание и последующее вспоминание англоязычной лексики студентами технических специальностей. Уточняется процесс работы мозга и памяти во время просмотра видео на занятии. Согласно проанализированным данным, фрагменты англоязычных фильмов и программ являются ценными материалами для обучения английскому языку как иностранному. Это было проверено экспериментально. Указаны результаты влияния аутентичных видео на запоминание и вспоминание английской лексики студентами, а также на их мотивацию к продолжению изучения английского языка.
\end{abstract}

Ключевые слова: видео, английский, лексика, студенты технических специальностей. 